majority of cases (proforma completion and referral to SHIP). There were low levels of accurate coding.

\section{P148 AN AUDIT ON MANAGEMENT OF AFTERCARE FOR VICTIMS OF SEXUAL ASSAULT ATTENDING A DEDICATED AFTERCARE CLINIC}

Vinod Kumar, Sashi Acharya, Joseph Arumainayagam*. Walsall Healthcare NHS Trust, WalsallWest Midlands, UK

\subsection{6/sextrans-2016-052718.202}

Background/introduction A dedicated sexual assault aftercare clinic was set up at the integrated sexual health service to provide care for the victims of sexual assault. British Association for Sexual Health and HIV (BASHH) guidelines provide auditable measures to compare standard of care provided by services. We wanted to assess and improve the service offered to victims by the dedicated clinic.

Aim(s)/objectives To evaluate current clinical practice in the management of victims of sexual assault against the auditable outcome measures in the guidelines and improve the quality of care provided by communicating the findings, recommendations and action plans to team members.

Methods Retrospective review of all victims who attended the clinic between January 2015 and $31^{\text {st }}$ September 2015 was performed. Cases were identified from coding used in the clinic. A standard data collection sheet developed on the basis of the BASHH guidelines was used.

Results Of the 53 victims identified, 96\% were women, 83\% were white, $13 \%$ were alcohol/drug related and $25 \%$ were under 18 years of age. $57 \%$ were referred by the sexual assault referral centre.96\% reported one assailant and 55\% were known to the victim. 100\% had HIV risk assessment and were offered PEPSE if indicated. 98\% were offered forensic examination if applicable, 93\% emergency contraception if needed. Offer of prophylaxis against sexually transmitted infections: chlamydia $74 \%$, gonorrhoea 62\%, Trichomonas 49\%. Offer of baseline testing for chlamydia 98\%, gonorrhoea 100\%, trichomonas 64\%, syphilis HIV and hepatitis B \& C 100\%. Documentation of a plan for repeat STI testing 93\%, documentation of offer of vaccination against hepatitis B 94\% and assessment of child protection needs if under 18 years $77 \%$.

Discussion/conclusion Areas to improve: documentation of a self-harm risk assessment, offer of emergency contraception, recording of a discussion of need for pregnancy test in 3 weeks after emergency contraception, documentation of offer of prophylactic treatment for chlamydia, gonorrhoea and trichomonas and documentation of an assessment of child protection needs if the victim was under 18 years of age. This will be re-audited in 6 months.

\section{P149 PATTERNS OF SEXUAL BEHAVIOUR AMONG TRANSGENDER INDIVIDUALS IN MELBOURNE, AUSTRALIA 2011-2014}

\footnotetext{
${ }^{1,2}$ Clare Bellhouse, ${ }^{1,2}$ Sandra Walker* ${ }^{*}{ }^{1,2}$ Christopher Fairley, 1,2Lenka Vodstrcil, ${ }^{2}$ Catriona Bradshaw, ${ }^{1,2}$ Marcus Chen, ${ }^{1,2}$ Eric Chow. ${ }^{1}$ Melbourne Sexual Health Centre, Melbourne, Australia; ${ }^{2}$ Monash University, Melbourne, Australia
}

10.1136/sextrans-2016-052718.203

Background/introduction Literature on the healthcare needs of transgender individuals is limited in Australia.
Aim(s)/objectives The aim of this study was to investigate the demographic characteristics, risk behaviours and STI/HIV positivity among male-to-female (MTF) and female-to-male (FTM) transgender individuals attending a sexual health clinic in Melbourne, Australia, between 2011 and 2014.

Methods A retrospective cohort analysis among 133 transgender individuals was conducted based on the first visit of the study period. Demographic characteristics, sexual behaviours, and HIV/STI positivity were examined.

Results 77 MTF, 28 FTM, and 28 unreported transgender status, attended 558 consultations with a median of two [IQR 1-5] visits. $70 \%$ percent attended for their first ever visit. Reassignment hormone use was $63 \%$ and surgery 27\%. 11\% had a history of injecting drug use, $74 \%$ were single/never married. In the last 12 months, 21\% had sex overseas and $11 \%$ attended for counselling. Low median male sexual partners 1 [IQR 1-5] and female sexual partners 2 [1-4] were reported. MTF were more likely to be overseas born, older and work currently as a sex worker than FTM. STI positivity was $7 \%(\mathrm{n}=8)$ chlamydia; $5 \%(\mathrm{n}=6)$ gonorrhoea and 5\% $(\mathrm{n}=6)$ syphilis and HIV 3\% $(n=1)$. There were no differences in positivity between MTF and FTM.

Discussion/conclusion In the Australian context STIs, HIV and sexual risk behaviours may differ to other developing and first world countries and therefore the healthcare needs may differ. Attention to differences in MTF and FTM transgender persons must be considered in health care.

\section{P152 RECOGNITION OF LGV LYMPHADENITIS IN MSM}

${ }^{1}$ Olamide Dosekun*, ${ }^{2}$ Rebecca Simons, ${ }^{2}$ Helen Iveson, ${ }^{2}$ Katie Conway, ${ }^{2}$ John White. ${ }^{1}$ Imperial College Healthcare NHS Trust, London, UK; ${ }^{2}$ Guy's and St. Thomas' NHS Foundation Trust, London, UK

\subsection{6/sextrans-2016-052718.204}

Background There is a sustained high rate of lymphogranuloma venereum (LGV) amongst men who have sex with men (MSM) in the UK, with the highest annual number of diagnoses reported in 2015, yet prompt diagnosis of LGV, particularly from nonrectal sites, eludes clinicians.

Aims We present 4 cases highlighting the ongoing challenge of recognition of LGV lymphadenitis, particularly outside GUM settings, and challenges with diagnosis and management.

Case reports 4 MSM (3 with well-controlled HIV on antiretroviral therapy, 1 HIV negative) presented to their GPs with unilateral groin swellings, and were referred to haematology or surgical teams for investigation. Investigations included ultrasound, CT/MRI of the groin as well as fine needle aspiration, and in 2 cases surgical exploration followed by node excision. None of the patients had symptomatic proctitis, and triple-site NAAT swabs for Chlamydia trachomatis (CT) were negative, although 1 patient had previously diagnosed but untreated urethral CT one month prior. In 1 case, CT serology (WIF) showed a high L2 titre of $>1: 4000$. In all cases, a 21-day course of doxycycline was commenced between 10-45 days from initial presentation. There was slow resolution of the lymphadenitis in 2 patients, necessitating a prolonged course of doxycycline (5 weeks), and addition of 7 days of azithromycin $500 \mathrm{mg}$ once daily, respectively.

Conclusion Early recognition and management, including prompt aspiration/drainage of buboes and appropriate antibiotic treatment are key to management of LGV lymphadenitis. Poor 
penetration of antibiotics into abscesses and residual inflammation may delay clinical resolution compared to proctitis cases.

\section{P155 TRANSDERMAL OESTROGEN PREVENTS CYCLICALLY- RECURRENT GENITAL HERPES}

Peter Greenhouse. Bristol Sexual Health Centre, Bristol, UK

\subsection{6/sextrans-2016-052718.205}

Background Some women suffer cyclical recurrences of genital herpes (c-RGH) immediately prior to menstruation, which are effectively prevented using aciclovir in the luteal phase only. This is more likely to occur in perimenopausal women whose immunity is diminished by premenstrual dysphoric disorder (PMDD), which is treatable with transdermal estradiol.

Aim To observe the frequency of herpes recurrences in women commencing estradiol treatment for perimenopausal PMDD.

Methods 12 perimenopausal women median age 41 years (range 36-45) presented between 2006-15, each meeting the criteria for PMDD subsequently defined in DSM-5. Each had at least 4 consecutive monthly episodes of c-RGH (culture-proven HSV2) before some took luteal-phase aciclovir, then all switched to transdermal 17 -beta estradiol gel $0.5 \mathrm{mg}$ daily for 14 days in the luteal phase or continuously for those using Mirena. Subjects self-reported mood with a modified daily symptom chart and herpetic symptoms over 9 months follow-up during which no aciclovir was taken pre-emptively. Intention-to-treat analysis included 10 cycles where treatment was omitted in error and both conditions recurred.

Results All women experienced substantial or complete relief of PMDD in all but three treated cycles. Only 13 symptomatic cRGH episodes occurred on treatment in 108 woman-months' observation.

\begin{tabular}{|c|c|c|}
\hline & PMDD & Herpes \\
\hline Total episodes observed in 9 months (I.T.T.) & 13 & 23 \\
\hline $\begin{array}{l}\text { Mean episodes per month Observed/Expected } \\
\text { (1.0) }\end{array}$ & 0.12 & 0.21 \\
\hline Probability (Student's t-Test) & $<0.001$ & $<0.01$ \\
\hline
\end{tabular}

Conclusion Transdermal estradiol treatment is a novel and biologically plausible method of preventing cyclically-recurrent genital herpes as it stabilises the hormonal milieu and diminishes immune suppression caused by PMDD.

\section{P156 A RARE CASE OF LYMPHANGIOMA CIRCUMSCRIPTUM OF THE PENIS}

Savidya Adikari*, Mannampallil Samuel. King's College Hospital, London, UK

\subsection{6/sextrans-2016-052718.206}

Introduction Lymphangioma Circumscriptum (LC) is a vascular malformation resulting from a developmental anomaly of the lymphatic system. The common sites for the anomaly include trunk, axilla, thigh, buttock area and the oral cavity. It is a rare for LC to occur on the penis.

Aim To increase awareness of this rare condition which may mimic sexually transmitted infections such as genital warts.
Methods Review of clinical notes and case presentation.

Results Description of the case: A 47 years old Afro-Caribbean man presented with a long-standing wart-like lesion on the dorsal aspect of his penis. Treatment in the past included cryotherapy and podophyllotoxin. There were no symptoms of itching, bleeding, change in size or pigmentation. The initial clinical impression was a genital wart. However on examination it was smooth to palpation despite its warty appearance. An excision biopsy was performed for both diagnostic and therapeutic purposes. Histology results showed penile LC.

Discussion LC is the commonest superficial type of lymphangiomas. Penile LC is rare and it maybe congenital or acquired. There was no identifiable predisposing factor in our case. LC presents with varying sizes of persistent vesicles, which are saccular dilations arising from underlying lymphatic vessels. Incidence of LC is high soon after birth. The vesicles may undergo verrucous changes and give the appearance of warts and therefore they may be mistaken for genital warts or molluscum contagiosum. Surgical treatment is the mainstay of treatment for LC.

\section{P157 SEXUAL HEALTH \& CONTRACEPTION: DEVELOPING A ONE STOP SHOP SERVICE USING A COLLABORATIVE APPROACH BETWEEN A LOCAL AUTHORITY, ACUTE AND COMMUNITY TRUSTS}

${ }^{1}$ Jenny Whetham*, ${ }^{2}$ Stephen Nicholson, ${ }^{3}$ Vicky Fenwick, ${ }^{1}$ Gillian Dean. ${ }^{1}$ Brighton and Sussex University Hospitals NHS Trust, Brighton, UK; ${ }^{2}$ Brighton and Hove City Council, Brighton, UK; ${ }^{3}$ Sussex Community Trust, Brighton, UK

\subsection{6/sextrans-2016-052718.207}

Background/introduction This city on the South East coast has a high proportion of young people/LGBT with some of the highest STI/HIV rates in England (2013 gonorrhoea 162.1/100,000; HIV prevalence $8 / 1,000)$. GUM \& contraception services were historically provided by two separate NHS Trusts. Transfer of public health responsibility to the Local Authority (LA) in 2013 led to service review.

Aim(s)/objectives To deliver an efficient and accessible multi-disciplinary sexual health and contraception service.

Methods City-wide public consultation favoured a one-stop-shop integrated service. Pathway Analytics ${ }^{C}$ sexual health tariff was accepted by LA/providers as a transparent \& fair payment mechanism. Following legal advice LA gave the commissioner permission to negotiate a new contract with existing providers, moving to a competitive tender process if unsuccessful.

Results The contract was awarded to existing providers in April 2015. The local Sexual Health Programme Board ensured all stakeholders were engaged in service review. A staged approach was followed to deliver an integrated service. The tariff was introduced allowing fair remuneration for combined services at diverse sites across the city. Trusts have established a steering group to ensure safe governance across legal, financial \& clinical frameworks \& robust risk management processes across both organisations.

Discussion/conclusion Innovative thinking by the LA allowed service re-design by negotiation with existing providers avoiding a competitive tender process. Good working relationships within the sexual health network allowed a collaborative approach to service improvement. Despite the challenges of two Trusts working together with different organisational accountabilities, a 'one-stop-shop model' has been successfully introduced without destabilising HIV services. 